\section{A rapid method for the detection of ferritin in serum}

M. R. BEAMISH ${ }^{1}$, P. LlEWELlin, and A. JACOBS From the Department of Haematology, Welsh National School of Medicine, Cardiff

Ferritin is one of the main iron storage compounds in the body. It is found mainly in the cytoplasm of reticuloendothelial cells, liver cells, and developing red cells in the bone marrow. Its occurrence in the circulating plasma has been described in normal subjects and in subjects with liver disease, malignant disease, severe haemolytic anaemia, and disorders of iron storage. The exact significance of circulating ferritin is not clear and the present method was devised in order that a large number of sera could be screened rapidly for the presence of small amounts of ferritin.

The method described utilizes the technique of counter-immuno-electrophoresis (Gocke and Howe, 1970). This allows small amounts of antigen to be detected by specific precipitation with antibody in one to two hours. Its sensitivity is comparable to that of previously described qualitative and quantitative methods.

\section{Methods}

Ferritin was prepared from human spleen and human 'M.R.B. is in receipt of a grant from Tenovus. Received for publication 26 November 1970. liver by a modification of the method used by Granick (1943). Tissue was sliced and water added to a total volume of 500 to $1000 \mathrm{ml}$. After homogenization the tissue was heated to $75^{\circ} \mathrm{C}$ for 20 minutes. The supernatant, after cooling and filtration, was treated with acetic acid to bring the $p \mathrm{H}$ to $4 \cdot 6$. All precipitated protein was removed by centrifugation and a clear supernatant was adjusted to neutral $p \mathrm{H}$ with dilute $\mathrm{Na} \mathrm{OH}$. When the clear brown supernatant was ultracentrifuged at $60,000 \mathrm{~g}$ for $90 \mathrm{~min}$ the suspended ferritin collected in a small button at the bottom of the tube. The precipitate was redissolved in $0.9 \%$ saline and further purified by passage through a Sephadex G200 column. The ferritin fraction from this column was passed through a DEAE cellulose anion exchange resin using Tris- $\mathrm{HCl}$ buffer at $p \mathrm{H} 7.5$ and a $0.02-0 \cdot 5 \mu$ gradient. The final preparation had an iron content of $16 \%$. Its purity was shown by cellulose acetate electrophoresis and immunoelectrophoresis against anti-ferritin serum and antihuman whole serum.

New Zealand white rabbits were used for the preparation of an antihuman ferritin serum. One mg of ferritin together with Freund's complete adjuvant was injected into the hind leg of each rabbit. The injection was repeated three times at monthly intervals. Two to three weeks after the final injection of antigen the rabbits were bled and the antisera collected and stored in aliquots at $-20^{\circ} \mathrm{C}$. Quantitative estimations of ferritin iron and protein were carried out using a modification of the method of Reissman and Dietrich (1956).

For counter immunoelectrophoresis glass projection slides ( 3 in. $\times 3$ in.) were coated with $10 \mathrm{ml}$ of $0.85 \%$ Agarose in $0.05 \mathrm{M}$ veronal buffer at $p \mathrm{H} 8 \cdot 2$.

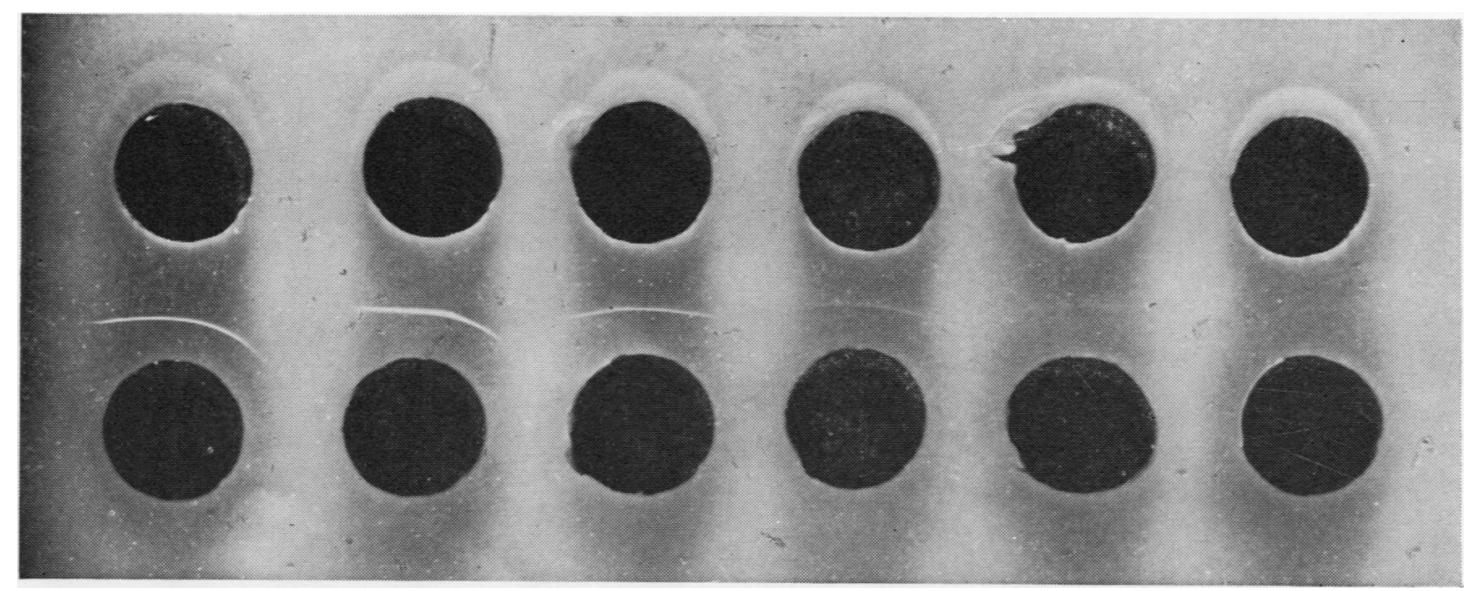

Fig. 1. Counterimmunoelectrophoresis plate after one hour.

Top row of wells: (left to right) serum (30 $\mu \mathrm{g}$ ferritin iron per $100 \mathrm{ml})$ neat $1: 2,1: 4,1: 6,1: 8,1: 10$.

Bottom row of wells: antihuman spleen ferritin. 
Parallel rows of wells $5 \mathrm{~mm}$ in diameter were cut in the agar $3 \mathrm{~mm}$ apart. Up to three double rows of wells could be accommodated on each slide.

Control sera containing known amounts of ferritin or test sera were placed in the rows of wells nearest the cathode, while the antiferritin serum was placed in the row of wells nearer the anode. Electrophoresis was carried out in a tank filled with veronal buffer at pH 8.2 at room temperature and with a constant current of 15 milliamps per slide. Between each double row of wells the antigen and antibody migrate towards one another and if ferritin is present a precipitating band appears which is easily visible after one hour. The slides may be washed in $0.9 \%$ saline to clarify the precipitation lines. The appearance after one hour's passage of current is shown in Figure 1.

\section{Results}

Serum containing antihuman spleen ferritin has normally been used for our tests. All antiferritin sera produced a precipitation line only with ferritin. No precipitation occurred with normal whole sera, haemoglobin, or transferrin. Dilution of the antiserum gave equally satisfactory results from 1 in 10 to 1 in 200. A dilution of 1 in 50 was used for routine purposes. Sensitivity of the method for the detection of ferritin iron was determined using serial dilutions of human ferritin in normal human serum. The minimum concentration of ferritin iron detectable appeared to be about $0.04 \mu \mathrm{g}$ iron per millilitre. When pathological sera containing ferritin were used it was found that a concentration of $0.04 \mu \mathrm{g}$ ferritin iron per $\mathrm{ml}$ gave an easily detected positive result. When serial dilutions of pathological sera were made in normal serum there did not seem to be any relationship between the actual concentration of ferritin iron and the highest dilution giving a positive precipitation reaction in the range 0.025 to $0.075 \mu \mathrm{g}$ per ml.

\section{Comment}

Ferritin prepared from fresh human spleens obtained $\overrightarrow{0}$ at splenectomy has proved a valuable antigen for the production of antisera. Spleens have been obtained from patients suffering from haemolytic anaemia, idiopathic thrombocytopenic purpura, and traumatic rupture. Antihuman spleen ferritin was normally $\stackrel{N}{\subseteq}$ used but antisera to human liver ferritin showed o complete cross reaction and gave identical results $\infty$ with ferritin obtained from human liver or spleen. The use of rabbit antisera prepared with horse ferritin gave ill defined precipitation lines with human ferritin although precipitation from ferritin in $\mathbb{D}$ solution was complete when the mixtures were left at $4^{\circ} \mathrm{C}$ for several days. Previously described methods for the detection of ferritin in serum are time con- $\mathbb{\Phi}$ suming and rather cumbersome (Aungst, 1966). The present method is simple and rapid in performance.

\section{References}

Aungst, C. W. (1966). A specific and sensitive method for the detection of ferritin in body fluids. J. Lab. clin. Med., 67, 307-313.

Gocke, D. J., and Howe, C. (1970). Rapid detection of Australia antigen by counterimmunoelectrophoresis. J. Immunol., 104, 1031-1032.

Granick, S.(1943). Ferritin IV. Occurrence and immunological properties of ferritin. J. Biol. Chem., 149, 157-167.

Reissman, K. R., and Dietrich, M. R. (1956). On the presence of ferritin in the peripheral blood of patients with hepatocellular disease. J. clin. Invest., 35, 588-595. 